LAW, ETHICS, AND MEDICINE

\title{
Does it matter that organ donors are not dead? Ethical and policy implications
}

\author{
M Potts, D W Evans
}

See end of article for

authors' affiliations

\section{Correspondence to:}

Professor M Potts, 5400

Ramsey Street, Fayetteville,

NC 28311 - 1498, USA;

gratiaetnatura@yahoo.

com

Received 11 August 2004 In revised form

29 September 2004

Accepted for publication

11 October 2004
J Med Ethics 2005;31:406-409. doi: 10.1136/jme.2004.010298

The "standard position" on organ donation is that the donor must be dead in order for vital organs to be removed, a position with which we agree. Recently, Robert Truog and Walter Robinson have argued that (1) brain death is not death, and (2) even though "brain dead" patients are not dead, it is morally acceptable to remove vital organs from those patients. We accept and defend their claim that brain death is not death, and we argue against both the US "whole brain" criterion and the UK "brain stem" criterion. Then we answer their arguments in favour of removing vital organs from "brain dead" and other classes of comatose patients. We dispute their claim that the removal of vital organs is morally equivalent to "letting nature take its course", arguing that, unlike "allowing to die", it is the removal of vital organs that kills the patient, not his or her disease or injury. Then, we argue that removing vital organs from living patients is immoral and contrary to the nature of medical practice. Finally, we offer practical suggestions for changing public policy on organ transplantation. l: a recent article, Robert Truog and Walter Robinson note: "The practice of organ transplantation has been wedded to the concept of brain death for most of its history". ${ }^{1}$ The link "is the 'dead donor' rule, which requires that patients be declared dead before the removal" of unpaired vital organsfor example, heart, liver, or two paired vital organs (such as kidneys). ${ }^{1}$ Movement toward changing the criteria of death from cardiopulmonary to brain based criteria was already taking place at Cape Town in 1967, due to pressure for a viable heart for transplantation. ${ }^{2-8}$ The consequence of the recipient's short survival was, as the BMJ's deputy editor put it, "a euphoric, uncontrolled epidemic of heart transplantation around the world". ${ }^{9}$ This, together with demand for other organs which required that they be perfused until their removal, necessitated "the production of a set of legal and philosophical justifications" ${ }^{\prime 2}$ for procedures that would otherwise be seen as assault. In the United States, the Harvard ad hoc committee for the determination of brain death proposed, in 1968, a new set of criteria for death based on "irreversible coma" with "no discernible central nervous system activity"10 (italics in original). This report paved the way for the 1981 President's Commission report, ${ }^{11}$ which supported "whole brain" criteria for death-criteria enshrined in the Uniform Determination of Death Act (UDDA), which is now law in almost all US states and the basis of "accepted practice" in many parts of the world. Despite attacks upon the coherence and empirical adequacy of such whole brain criteria, $^{12}{ }^{13}$ the President's Commission report and UDDA remained the "bible" for diagnosis of death in the US. In the last ten years, fresh attacks on brain death criteria ${ }^{14-17}$ have eroded their perceived invulnerability. Their conceptual and empirical foundations are collapsing. Calixto Machado and Alan Shewmon, in a newly published anthology, ${ }^{18}$ note that there are still worldwide controversies over the very concept of human death and the putative neurological grounds for diagnosing it (whole brain, brain stem, and higher brain formulations of death). There are also disagreements over the diagnostic criteria of brain death, whether clinical alone, or clinical plus ancillary tests. Moreover, a group of scholars who were strong defenders of brain based criteria of death are now favouring a circulatory/respiratory view. Hence, the debates on human death are far from concluded.
This trend is reflected in the paper by Truog and Robinson, who note that the concept of brain death "fails to correspond to any coherent biological or philosophical understanding of death". ${ }^{1}$ We believe this claim well founded. There were never sound empirical grounds for criteria of death based on the loss of testable brain function while the body remains alive. One difficulty is the near impossibility of diagnosingwith the necessary certainty- the "irreversible cessation of all functions of the entire brain, including the brain stem" ${ }^{\prime 11}$ while the rest of the body remains alive. The Harvard testsessentially of brain stem mediated reflexes and ventilator dependence in patients whose coma appeared irremediableclearly lacked the power to make that diagnosis. The many protocols now in use worldwide fail similarly. Indeed, their very number ${ }^{19} 20$ proclaims the fact that the syndromes they diagnose cannot be one and the same true entity. And prominent among the variations is the apnoea test, which may lead to the misdiagnosis of respiratory centre failure if inadequately stimulating and, if stringently applied, may itself be the cause of death. ${ }^{21}$

Truog and Robinson acknowledge that many patients currently diagnosed "brain dead" do not, in fact, meet the American legal requirements governing that practice. They note that many retain demonstrable brain function-and that this knowledge, which should be a challenge to those certifying death on the basis that there is no such activity-is set aside as not "significant". ${ }^{1}$ That dismissal is similar to the stance assumed by those who supported the brain stem death criteria which became UK policy in 1979. They promulgated a set of prognostic criteria, first published in 1976, with a directive that they were to be used thenceforth as criteria for the diagnosis of death. ${ }^{22}$ This conceptual confusion was compounded by the assumption that permanent incapacity for consciousness could be safely assumed when some brain stem mediated reflexes were absent in comatose patients whose apnoea appeared permanent. Like the US "whole brain criteria," the UK criteria-held to define death conceptualised as permanent loss of the capacity for consciousness and the capacity to breathe spontaneously ${ }^{23}$ - did not

Abbreviations: EEG, electroencephalogram; UDDA, uniform determination of death act 
require the electroencephalogram (EEG) as a test for continuing life in the brain. If recorded, continuing EEG activity was to be disregarded-along with other evidence of persisting brain function-as lacking "significance." It remains unclear, however, on what grounds such activity is disregarded, bearing in mind the present very limited understanding of brain physiology.

Although the term "brain death" is supposed to have gone out of use in the UK, ${ }^{22}$ comatose, ventilator/dependent patients are still being certified "dead" for transplant purposes using similar tests but on the basis of some idiosyncratic concept that remains far from clear. In the US, criticisms of brain death criteria have remained a matter of academic debate and have not filtered down to the level of public policy. The UDDA and the "dead donor rule" still govern transplantation practice. Truog and Robinson, like others before them, ${ }^{24}{ }^{25}$ propose the abandonment of all obfuscation where requests for transplantable organs are concerned. They accept that "brain dead" individuals are alive. The issue then becomes: "Given that brain dead individuals are not dead, is it morally acceptable to remove their organs for transplantation?"

Truog and Robinson answer "yes," and "propose that the ethics of organ donation be based on the ethical principles of non-maleficence and respect for persons rather than on brain death and the dead donor rule". ${ }^{1}$ They "propose that sometimes the harm of dying is sufficiently small that patients should be allowed to voluntarily accept that harm if it makes organ donation possible" ${ }^{\prime 1}$ They are not in favour of just anyone donating their vital organs. Rather, they accept the idea that there must be some "threshold" state above which organ donation would not be permitted. ${ }^{1}$ It would be permissible to use as donors at least two classes of patients who had given prior consent: the "permanently unconscious" and the "imminently dying". ${ }^{1}$ Ultimately, it would be up to "society" to determine the minimal threshold of lively existence below which donation would be permitted. ${ }^{1}$ They suggest that organ donation from the "permanently unconscious" be limited to patients declared "brain dead" by current standards, because of uncertainty about the "capacity for consciousness" in patients in a persistent vegetative state or in anencephalic newborns. ${ }^{1}$ The "imminently dying" group should initially be limited "to those patients completely dependent on life support, in whom death would be expected within minutes of withdrawal of that support, and in whom no treatment alternatives are available or desired". This would include "patients with cervical quadriplegia who desired withdrawal of mechanical ventilation or patients on cardiac support devices who refused continuation of that support or other treatment alternatives". ${ }^{1}$ Such patients would normally grant permission for organ removal themselves, "removing any concerns about the legitimacy of surrogate decision making in cases like this". ${ }^{1}$ Practically, these limitations imply that there is "a large gap between the category of patients permitted to have withdrawal of life support and the category of patients permitted to donate organs" ${ }^{\prime 1}$ The former group will be the larger, because more categories of patients would be allowed to refuse life prolonging treatment than those allowed to donate their organs.

For Truog and Robinson, the case for taking organs from still living donors depends upon "shifting the key ethical question from 'Is the patient dead?' to 'Are the harms of removing life sustaining organs sufficiently small that patients or surrogates should be allowed to consent to donation?". . Their answer to the second question is "yes", at least for some classes of patients. These authors believe that the current practice of harvesting organs from donors "who meet brain death criteria....[is] clearly ethical—not because the patients are dead, but rather because they have been rendered permanently unconscious from an overwhelming brain injury". ${ }^{1}$ As far as the larger class of patients eligible for "non-heart beating organ donation" is concerned, a group that includes individuals who do not meet brain death criteria, they suggest that rather than removing their organs after a set period of time following cardiac arrest, it would be better to remove their organs before ischaemic cardiac arrest. This not only overcomes the problem of "orchestrated death in these protocols", it also "optimise[s] both the number and the viability of the organs obtained". ${ }^{1}$

To answer the charge that vital organ removal kills the living patient, Truog and Robinson argue that there is a parallel between organ procurement and ventilator withdrawal: "In both ventilator withdrawal and organ procurement, the physician acts, and this act is the most proximate cause of the patient's death. In both cases, the physician is not morally responsible for the patient's death-the morally relevant cause of death is the patient's disease. In both cases, the physician is acting with the patient's consent in ways that respect the wishes of the patient and that are in the pursuit of morally worthwhile ends." ${ }^{1}$

Once we recognise that the dead donor rule is not morally necessary for organ procurement, the "concept of brain death will then disappear from textbooks, illustrating the degree to which the concept was never more than a social construction, developed to meet the needs of the transplantation enterprise during a crucial phase of its development". ${ }^{1}$

We contend that Truog and Robinson's arguments for the moral acceptability of organ procurement once the dead donor rule is eliminated are unsuccessful, and that the unacceptability of such transplantation should lead to changes in current policy. We believe that removing vital organs from a still living donor is the taking of innocent human life. The argument that such removal is morally no different from "allowing to die" by removing a ventilator is seriously flawed. When a ventilator is removed from an apnoeic comatose patient, it is the disease or injury that causes the loss of the patient's ability to breathe spontaneously. As Margaret Somerville notes: "the withdrawal of life support treatment such as respiratory support involves a situation of multiple causation in which one cause (respiratory failure) is sufficient to cause death; the other cause (turning off the respirator) is not sufficient in the absence of respiratory failure ${ }^{\prime \prime}{ }^{26}$ The situation is different when vital organs are removed from a patient. Removing a vital organ, such as the heart, directly causes the death of the patient, and is not merely allowing the effects of disease or injury to take their course. It is the organ removal surgery that kills the donor. In addition, withdrawal of life support may be an acceptable omission of burdensome treatment, rather than an act that is more likely to involve an intent to kill the patient. The issue in removing vital organs from brain dead individuals is not, therefore, whether to withdraw burdensome life support from a dying patient but whether such organ removal is a morally acceptable form of killing. Truog and Robinson say it is. As Truog says elsewhere, organ transplantation involves "a form of justified killing" since it does not "harm" "those who are permanently and irreversibly unconscious (patients in a persistent vegetative state or newborns with anencephaly) and those who are imminently and irreversibly dying" ${ }^{\prime 16}$

Truog and Robinson's proposals that unpaired vital organs be removed from "brain dead" and other classes of patients can be seen as the endorsement of killing people for their organs. One difficulty with this is that once utilitarian considerations are used to justify killing ventilator/dependent patients who are dying, those same considerations could also be used to justify killing non-ventilator/dependent patients or patients who are not dying.

Another major problem with doctors being involved in killing patients is that such a practice by medical professionals fundamentally distorts the nature of medicine itself. 
Edmund Pellegrino and David Thomasma have developed the idea that medicine is primarily a relationship between a sick or injured person needing help and the physician or other health care provider who is trained to provide such help. ${ }^{27}$ As such, medicine involves morality as part of its very structure, for there is an imbalance of power and knowledge between the health care provider and the patient (whose vulnerability, when ill, exacerbates this imbalance). This implies a responsibility for the health care provider (1) to have the requisite training and skills and to use those skills competently, and (2) to tell the patient the truth, for trust is necessary for the success of the relationship. It also implies the dictum, "first, do no harm", and the virtues of beneficence (helping the patient in a positive way), and justice.

The fundamental moral problem with killing patients (as opposed to allowing them to die) is that such a practice distorts the very nature of the doctor/patient relationship, since it involves a dangerous use of medical power. The doctor's specialised training gives him (or her) power over his (or her) patient in an intimate way. Using such training to kill subverts its purpose and can easily be used to justify killing other groups of patients on utilitarian grounds. Killing a patient by removing his organs is not legitimate even if he (or his family) requests it. Patient autonomy is not an absolute value that trumps all other values. No decision about life or death matters is ultimately "private", for human beings are by nature social creatures, who live in a web of relationships with other people. Decisions about life and death affect family members, friends, and medical staff. Since the latter are directly involved in removing organs from a donor, the patient's signing of an organ donor form is not a "private decision". Doctors are morally obliged to refuse requests that involve illegitimate exercise of medical power. Requests (oral or written) do not automatically imply an obligation to comply with them. Even if an individual is "brain dead", killing him for the good of others cannot be justified. Crossing that line is dangerous for patients, who are some of the weakest members of society and dependent upon its protection.

If, as we have argued, it is morally wrong to kill patients for their organs, what difference does this make for public policy? If it were generally recognised that "brain dead" patients are alive, would the medical community and general public support a ban on the procurement of organs for transplant from them? Or would they take a position similar to that of Truog and Robinson, holding that even if organ donors are alive, the loss of their lives does such little harm that removing their organs is morally acceptable? There might, perhaps, be support from some for the Truog and Robinson proposal to extend the pool of organ donors beyond those who are "brain dead". Others, however, might be deeply disturbed that living patients are being used as organ donors and would refuse to sign organ donor cards. A key point is that individuals are not able to understand the issues, and therefore cannot give informed consent to organ donation, if they do not receive accurate information about the procedure. They should know that, in current practice, most organs for transplant are taken from "brain dead" individuals $^{28}$ who are not dead in the sense that their circulation and respiration have ceased, or that their brains are really and truly dead. ${ }^{22}$ They should be aware that the diagnosis of "brain death" is not soundly based or universally accepted, ${ }^{1}{ }^{14}$ and that there are serious questions about its constituting the death of the person. ${ }^{29}$ The public should also be aware that there remains uncertainty regarding the generation of consciousness in the brain, and that it is not always clear that there is no capacity for consciousness remaining in individuals declared "brain dead". ${ }^{30}$
Much of the information given to the public regarding organ donation and the declaration of death comes through literature in support of people signing organ donor cards. Currently, the statement on organ donor cards asserts that organs may be taken "after my death". We believe that such wording should be changed to reflect the fact that "brain dead" individuals are not dead in the usual understanding of what death is. Explanatory literature accompanying organ donor cards should be frank that a "brain dead" donor's heart is beating during part of the organ removal surgery. There should be open public discussion and debate on the determination of death instead of the current domination of the orthodox "whole brain death" (US) or "brain stem death" (UK) positions. Pluralism on the issue of the determination of death should be publicly acknowledged. Proposals to make organ donation the "default" unless the potential donor says otherwise ${ }^{31}$ should be rejected, since such policies are not only open to abuse, but also too easily allow patients who oppose brain death criteria to become organ donors against their wishes. Another difficulty is that such "presumed consent" cannot be valid unless all those eligible to be donors under these policies - that is, the public as a whole-fully understand the organ procurement procedures.

We welcome Truog and Robinson's admission that "brain dead" individuals are not dead and that brain death criteria were developed to allow vital organ donation, rather than being on a firm scientific or philosophical basis. We sharply disagree, however, with their position that it is morally acceptable for this to continue, albeit on some new understanding of what is being done. The general acceptance of the practice since 1968 (in the US) is irrelevant to its moral rightness or wrongness.

\section{Authors' affiliations}

D W Evans, Queens' College, Cambridge, Cambridge, UK

M Potts, Philosophy and Religion Department, Methodist College, 5400 Ramsey Street, Fayetteville, NC 2831 1-1498, USA

David Evans is a sometime consultant cardiologist to Papworth and Addenbrooke's Hospitals, Cambridge, UK. Professor Potts is Chair of the Philosophy and Religion Department and Associate Professor of Philosophy at Methodist College, Fayetteville, NC, USA

\section{REFERENCES}

1 Truog RD, Robinson WM. Role of brain death and the dead-donor rule in the ethics of organ transplantation. Crit Care Med 2003;31:2391-6.

2 Hoffenberg R. Christiaan Barnard: his first transplants and their impact on concepts of death. BMJ 2001;323:1478-80.

3 Potts $M$. Begging the question of when death occurs. http://bmj.bmijournals. com/cgi/eletters/323/7327/1478\#18238 (accessed 9 Nov 2004).

4 Evans DW. Barnard's first transplants and concepts of death. http:// bmj.bmijournals.com/cgi/eletters/323/7327/1478\#18279 (accessed 9 Nov 2004).

5 Hill DJ. Deception of organ donors. http://bmj.bmijournals.com/cgi/eletters/ 323/7327/1478\#18309 (accessed 9 Nov 2004).

6 Woodcock TE. Time for a new Human Organ Transplant Act? http:// bmj.bmijournals.com/cgi/eletters/323/7327/1478\#18387 (accessed 9 Nov 2004)

7 Jarvis GE. A history of death. http://bmi.bmijournals.com/cgi/eletters/323/ 7327/1478\#18468 (accessed 9 Nov 2004).

8 Coimbra CG. Global ischemic penumbra and irreversible loss of brain (or brain stem) function. http://bmj.bmijournals.com/cgi/eletters/323/7327/ 1478\#18780 (accessed 9 Nov 2004).

9 Smith T. Clinical freedom. BMJ 1987;195:1583.

10 Ad hoc committee of the Harvard Medical School to examine the definition of brain death. A definition of irreversible coma. JAMA 1968;205:337-40.

11 President's Commission for the Study of Ethical Problems in Medicine and Biomedical and Behavioral Research. Defining death: a report on the medical, legal, and ethical issues of the determination of death. Washington, DC: US Government Printing Office, 1981.

12 Byrne PA, O'Reilly S, Quay P. Brain death: an opposing viewpoint. JAMA 1979;242:1985-90.

13 Byrne PA, O'Reilly S, Quay PM, et al. Brain death - the patient, the physician, and society. Gonzaga Law Rev 1982-83;18:429-516.

14 Shewmon DA. "Brainstem death", "brain death" and death: a critical reevaluation of the purported evidence. Issues Law Med 1998;14:125-45. 
15 Shewmon DA. Chronic "brain death": meta-analysis and conceptual consequences. Neurology 1998;51:1538-45.

16 Truog R. Is it time to abandon brain death? Hastings Cent Rep 1997:27:29-37

17 Potts M, Byrne PA, Nilges RG, eds. Beyond brain death: the case against brain based criteria for human death. Dordrecht, The Netherlands: Kluwer Academic Publishers, 2000.

18 Machado C, Shewmon DA, eds. Brain death and disorders of consciousness. Dordrecht, The Netherlands, London, and Moscow: Kluwer Academic/Plenum Publishers, 2004

19 Wijdicks EFM. Brain death worldwide: accepted fact but no global consensus on diagnostic criteria. Neurology 2002;58:20-5.

20 Evans DW. Open letter to Professor Eelco F M Wijdicks, author of book on brain death. http://bmi.bmijournals.com/cgi/eletters/325/7364/598/ a\#27760 (accessed 9 Nov 2004).

21 Coimbra CG. Implications of ischemic penumbra for the diagnosis of brain death. Braz J Med Biol Res 1999;32:1479-87.

22 Evans DW. The demise of "brain death" in Britain. In: Potts M, Byrne PA, Nilges RG, eds. Beyond brain death: the case against brain based criteria for human death. Dordrecht, The Netherlands: Kluwer Academic Publishers, 2000.

23 Working group of the Royal College of Physicians. Criteria for the diagnosis of brain stem death. J Roy Coll Phys London 1995;29:381-2.
24 Kerridge $\mathrm{IH}$, Saul $P$, Lowe $M$, et al. Death, dying and donation: organ transplantation and the diagnosis of death. J Med Ethics 2000;28:89-94. 25 Woodcock TE. New act regulating human organ transplantation could facilitate organ donation. BMJ 2002;324:1099.

26 Somerville M. Death talk. Montreal and Kingston: McGill-Queens University Press, 2001.

27 Pellegrino ED, Thomasma CD. A philosophical basis of medical practice. New York: Oxford University Press, 1981.

28 Testa G, Klintmalm GB. Assessing suitability of the cadaver donor. In: Stuart FP, Abecassis MM, Kaufman DB, eds. Organ transplantation. Georgetown, TX: Landes Bioscience, 2000.

29 Jones DA. Metaphysical misgivings about "brain death". In: Potts $M$, Byrne PA, Nilges RG, eds. Beyond brain death: the case against brain based criteria for human death. Dordrecht, The Netherlands: Kluwer Academic Publishers, 2000

30 Hill DJ. Brain stem death: a United Kingdom anaesthetist's view. In: Potts $M$, Byrne PA, Nilges RG, eds. Beyond brain death: the case against brain based criteria for human death. Dordrecht, The Netherlands: Kluwer Academic Publishers, 2000

31 Nelson JL. The rights and responsibilities of potential organ donors: a communitarian approach. In: Arras J, Steinbock B, eds. Ethical issues in modern medicine [4th ed]. Palo Alto, CA: Mayfield Publishing Company, 1995.

\section{The use of generic or patent medicines in the Netherlands}

n September 1998 the Dutch Ministry of Health together with the Dutch Society of General Practitioners (LHV), the Royal Dutch Society of Pharmacists (KNMP), and the Dutch Patient and Consumer Federation (NPCF) published a pamphlet entitled: The same medicine in a different coat. Drugs without a trademark, equally effective, but cheaper. Patients could obtain a copy at the local pharmacy or in the waiting room of their general practitioner. It deals with the question whether the name of the patent drug should be written on the prescription or only the active (generic) component. This is important because, according to the authors, the costs of health care can be reduced without reducing the quality of the care if the doctor prescribes the generic form. It is also mentioned that another advantage of prescribing the generic form is that, contrary to the patent drug, it is known under the same name in all countries. This enables pharmacists and doctors everywhere to establish directly which drug the patient is taking. As a precaution it is also stated that, in some special cases, it remains necessary to administer the patent drug, for instance, if the right dose is not available in the generic form.

On 19 July 2003 there appeared in the national newspaper, Trouw, an advertisement, which contained a very different message. This time an association of leading pharmaceutical companies in the Netherlands, Nefarma, had replaced the Ministry of Health and the pharmacists (KNMP) as coauthors. In large print the readers were informed as follows: "Save money? Not at the expense of your health. Do not accept another medicine, another composition or dose. The government wants to save money, for instance, on the costs of drugs. Of course this should never be at the expense of your health. Especially for the elderly and the chronically ill patients, who regularly need medicines, such a policy would have great consequences. Also the health insurance companies are involved and are of the opinion that the lower the costs of medicines, the better. It is quite likely that in this tumult you, as a patient, can no longer determine what should be done. Without the doctor's and your permission, the pharmacist may not deviate from the medicine, written on the prescription". The advertisement includes a number of drawings: in one of these the doctor gives the patient a prescription for drug A and in another the pharmacist has exchanged this for drug $\mathrm{B}$, which the patient refuses to accept.

I believe that such an advertisement is unethical. The patient is made afraid that his treatment is interfered with in a detrimental way by the pharmacist. Recently de Visser, the director of Nefarma, published an article in a Dutch medical journal ${ }^{1}$ in which he clarified his opinion on this matter. De Visser makes it clear that it is illegal for pharmacists to deliver to the patient a generic drug if the doctor has written on the prescription a different (patent) medicine. He also stresses that only the physician knows the disease from which the patient suffers and that he is therefore the only one who can determine which medicine the patient needs. In this article the director of the Dutch Society of General Practitioners, H van Baasbank, reports that the society has: "received signals that without approval of their GP, patients have received from pharmacists an undesirable replacement of patent drugs by generic drugs". A member of the board of the Royal Dutch Society of Pharmacists (KNMP) presents his case in the same paper. He affirms that the pharmacist knows the regulations on what to do when there is a choice between generic and patent medicines. His motives are based on the price of the drug as long as the effect is the same. He reproaches Nefarma for creating this animosity between the parties solely because it fears loss of profit if more generic drugs are prescribed. It is clear that patients, who are, in general, not aware of the background of this power struggle, are bewildered. In my opinion the advertisement should never have appeared in the newspaper. The sooner the conflict is resolved by discussion between the parties, the better it will be for all concerned.

D O E Gebhardt Anna van Burenlaan 1, 2341 VE Oegstgeest, Netherlands; doe.gebhardt@planet.nl

\section{REFERENCES}

1 De Visser C. An opinionated attitude is not proper for the pharmacist. Med Contact 2003;58:1227-9. 